WEIDONG LI, Ph.D. ${ }^{1}$

E-Mail: wdli@bjtu.edu.cn

OLLI-PEKKA HILMOLA, Ph.D. ${ }^{2}$

(Corresponding author)

E-mail: olli-pekka.hilmola@lut.fi

JIANHONG WU, Ph.D. ${ }^{1}$

E-mail:wujh@bjtu.edu.cn

${ }^{1}$ School of Economics \& Management

Beijing Jiaotong University

Beijing, 100044, China

2 LUT University, Kouvola Unit

Prikaatintie 9, FIN-45100 Kouvola, Finland
Transport Planning

Review

Submitted: 28 Mar. 2019

Accepted: 4 Oct. 2019

\title{
CHINESE HIGH-SPEED RAILWAY: EFFICIENCY COMPARISON AND THE FUTURE
}

\begin{abstract}
High-speed railway (HSR) network building was initiated in China in the early 2000s, and full-scale construction began several years later as a larger use phase started in 2008. Thereafter, the expansion speed has been impressive. Network investment could be considered as a success, if evaluating the amount of high-speed railway usage already during the expansion phase. The diffusion models built in this research show that expansion in the network and growth of the passengers will continue at least until the following decade. The performance is evaluated in terms of DEA efficiency model. It is shown that efficiency started from very low levels, but it has been increasing together with the expansion of HSR network. Currently, the efficiency is near the level of the leading European High-speed (HS) countries (Germany and France). However, it is projected with linear model and by Bass diffusion models that the efficiency will reach Japanese and South Korean standards in the next decade. A somewhat larger network length with smaller relative growth of passengers, but with a higher growth of passenger-km seems to be able to reach even the frontier efficiency.
\end{abstract}

\section{KEY WORDS}

high-speed railways; efficiency; benchmarking; Bass diffusion model; future;

\section{INTRODUCTION}

In the recent decade a lot of changes and developments have taken place related to Chinese railways. The first larger-scale High-speed Railway (HSR) operations started in 2008. In 2003 the first line between Qinhuangdao and Shenyang was opened; [1, 2]), and in the late 2013 new ambitious international infrastructure investment program of One Belt and One Road was introduced [3, 4]. This latter program contains also a significant involvement of railway industry [5], and not only of building HSR in other countries, but also better freight connections as well as introducing continental landbridge trains directly from the Chinese cities to numerous European ones $[6,7]$. All of these programs have progressed significantly further, and they are characterized by the growth and change that have been present. As there is already a decade of data available from the start of HSR implementation, and its performance during the years, it could be for the first time roughly analysed, how it performs in comparison to other HSR countries. The Chinese HSR network is already bigger than the rest of the world in total [8]. Based on earlier studies, it has been indicated that the efficiency of Chinese railway companies prior to HSR expansion in 2007 was already rather high [9]. A similar conclusion was made from the international railway sector evaluations of passengers and freight with older data [10, 11]. Li et al. [12] concluded that the Chinese railway reform and implementation of HSR has enabled higher technical efficiency than before.

The international HSR efficiency comparisons have been rare as data availability is always an issue, and evaluations have been difficult to accomplish as in some countries HSR is still in the expansion phase. Doomernik [13] evaluated lately the HSR efficiency performance of the most important European and Asian countries, and he concluded that in general the Asian countries are more efficient and they have been significantly improving their performance in the recent years. However, for China, Doomernik [13] evaluated that in some respects the efficiency has been kept high, but overall there is still room to catch up with the leading Asian countries (like Japan). It should be noted that HSR efficiency evaluation is not only about operational efficiency or service issues. For example, in Italy the usage and implementation of HSR have been rather successful, but the construction was really costly [14]. However, in Spain the HSR network was built as too large due to thinking about the potential 
users and population of this country, and therefore, in the light of network invested the usage has been seen as less successful [14]. HSR network is never alone in providing transportation services, and the sole passenger transportation mode - in Japan the success of HSR could partly be explained by the lack of domestic airline competition [15]. The situation has been different in the European countries, where low-cost airlines have been taking market shares vigorously. In China the HSR network faced airline competition during its existence, and air transport used price cuts to take the market share back [15], mostly because HSR is often cheaper than using air [16, 17]. However, on many HSR routes in China the airlines lost volumes, and in some cases domestic airline services had been cancelled (e.g. Zhengzhou-Xi'an; [16, 17]). In only a limited number of countries HSR had been used within the transportation mode competition to enhance the efficiency of rail vs. air; however, with the right railway access charging the market share could be taken [18]. Despite these competition issues, HSR networks in Europe have brought clear long-term productivity gains (as compared to countries without HSR network; [19]). Also, studies of provinces, areas and cities of Japan [20] and China [21] indicate other social benefits from HSR investments.

The research purpose of this study is to compare the Chinese HSR system with the rest of the world, and to position its past and current performance, but also to sketch the future likely developments. The used efficiency measurement model is not ideal as variables available at UIC [22] are limited, if one wants to analyse all the key countries simultaneously. It would have been interesting e.g. to include in this research train runs of different countries, but these data were not available from all key countries. However, research work is one of the seminal research works from the global HSR evaluations, and it has opened work for other researchers in the field, and also unions and associations, in order to support more detailed efficiency studies in the future. The methodology applied in this research work is that of concentrating on one growing country in the HSR field, and the potential future outcomes of its efficiency in the following decade. As the rest of the leading HSR countries in the world (like Germany, France, Japan, Italy, and Spain) have already built their systems, and in many cases their increase in using these services has considerably matured, the future efficiency evaluation models may be developed by projecting with diffusion models the Chinese development through key variables of the efficiency measurement model. The research problem and the issues of this study could be stated as follows: What is the current performance of China's HSR as compared to the leading countries in the field? When could it catch up with other countries in its efficiency (if other countries do not invest or expand services in the following decade)? Is it possible for China to reach the highest efficiency countries?

This research is structured as follows: the following Section 2 analyses the Chinese HSR growth prospects through key variables of the used efficiency measurement model. The research methodology of this study follows in Section 3, which also analyses the used variables in details. The results of the efficiency measurement and future forecasts follow in Section 4. The research is concluded in Section 5, where further research issues in this field are proposed.

\section{CHINESE HIGH-SPEED RAILWAY GROWTH PROSPECTS}

High-speed railway network large-scale use started in China in 2008, and thereafter its usage and construction have both grown significantly, and this growth is still continuing. In the end of 2017 the official statistics [23] showed that the network size was 25,164 km, and the number of passengers using it was 1.75 bill., and passenger-km travelled reached 587,560 mill. These numbers are already significant in comparison to other leading high-speed railway countries. However, there is still some room left for the growth as scaled with population. In Japan the amount of HSR users as scaled to population is a little more than twice that of China. It is a similar difference (and room to grow further) in passenger-km with Japan and France. Regarding network size there exist countries having nearly twice as large High-speed (HS) network, like Germany and France as scaled to population. This is the justification for the Bass diffusion forecast models in the following - passenger amounts are somewhat above these multipliers, but the high HSR travel is expected to increase as the Chinese society continues its urbanization from around $60 \%$ level to eventually reaching the level of $70-80 \%[24,25]$, green reforms continue to be promoted through sustainable transportation modes, and the ageing population favours and uses the railways more. It should be emphasized that urbanization in the Chinese case does not necessarily have to end at the forecast level. Even today there are countries with urbanization level of above $90 \%$ (like 92\% in Japan and 98\% in Belgium; [26]).

While building the future projections through Bass diffusion model of high-speed railways to passenger amounts (Figure 1), passenger-km (Figure 2) and railway network length (Figure 3), there were certain difficulties in the process. Both passenger data showed S-curve based growth, but the railway network completion was possibly more fluctuating around the fitted curve (even having some linear features) or then having different values of overall size (final total size of the network), which was assumed in this research work (however, it is not rare for the Bass curves to have pauses in their 
development, like in telecommunications, where the Internet use was at a certain level and slowing down before the introduction of mobile Internet and $3 G / 4 G$ ). So, the railway track length in Figure 3 could take aggressive growth phase again in the forthcoming years, and it is basically a matter of decisions concerning the expansion of high-speed railway network with the construction delay. All Bass curves in the following were fitted with the principle of having the lowest absolute error to the realized values. Absolute error was minimised by altering the values of $p$ and $q$ by using MS Excel and its Solver package (GRG non-linear optimization algorithm; these are "high" scenarios in Figures 1 and 3). In the following it is assumed that the passenger transportation in the number of passengers is growing faster than passenger-kms in the high scenario (Figure 1). This is justified by the realized data - apart from the first years of operation (in 2009 and 2010) the growth of passengers has always been higher than passenger-km. It is also so that the amount of HSR passengers from the overall national Chinese railway transport is much higher (above 40\% in 2016) than the situation with passenger-km (below $40 \%$ in 2016; [8, 23]). However, speed advantage of the HSR

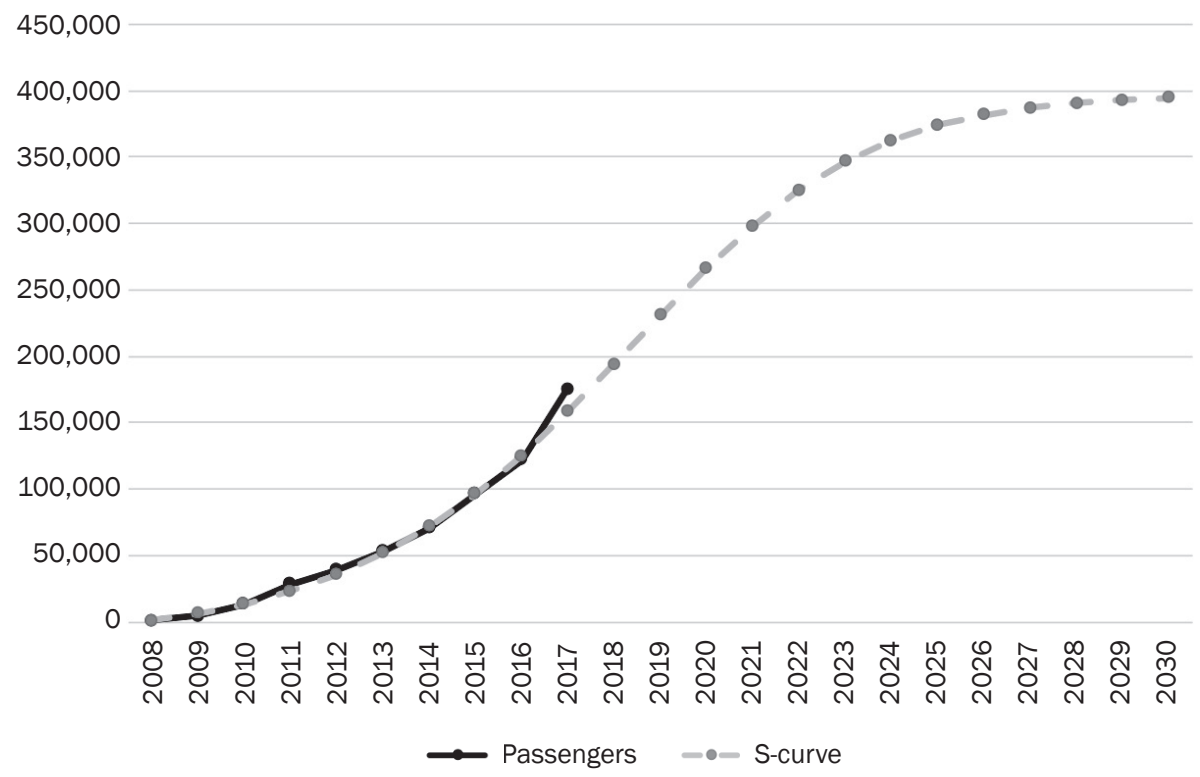

a) Low demand scenario $\left(m=397,440.1, p=0.0133, q=0.3434 ; R^{2}=0.992\right)$

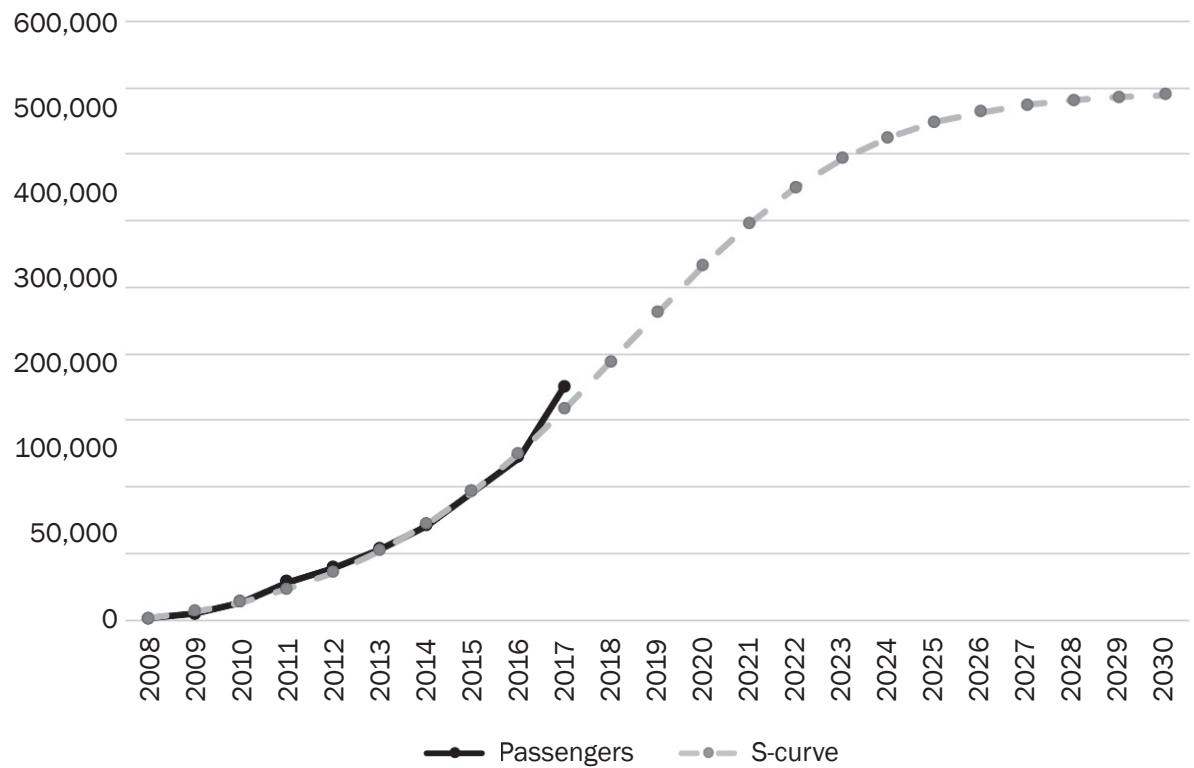

b) High demand scenario ( $m=550,000, p=0.0095, q=0.3234 ; R^{2}=0.994$ )

Figure 1 - Realized passenger amounts (in 10,000 persons) in Chinese high-speed railway network during 2008-2017, and S-curve based forecast up to the year 2030 
system is on longer distances (longer than 100-200 $\mathrm{km})$, and therefore, another scenario was developed where passenger numbers are growing less (Figure 1, "low"). These "low" scenarios were built with MS Excel Solver with such approach that GRG Non-linear optimization algorithm was given the opportunity to alter e.g. the size of the future HSR network in China. In this situation the Bass diffusion model forecast was basically the same for the market size in passenger-km model; however, in the railway network length it was lower than the used one, and similarly in the number of passengers it was lower.

In the last observation year, 2017, the passenger number on high-speed railway increased to 1.75 billion, and the growth overall resembled well the S-curve of Figure 1 ( $R^{2}$ values of 99.2-99.4\% in low and high scenarios). In Figure 1 it is assumed that the passenger numbers will increase up to 3.97 bill. or 5.5 billion in low and high scenarios, respectively (2.27-3.14 times higher as compared to the realized amount in 2017; significant future increase is also argued by other recent research works, like [2]). However, in Figure 1 these new levels are not completely achieved as passenger amounts in 2030 (some small growth is left for 2030 s in "high" scenario). The forecasting model assumes that innovative consumer demand had a multiplier ranging from 0.0095-0.0133. This is the lowest of all three models (Figures 1-3). However, imitative demand had a high multiplier as compared to all three figures, indicating that masses are reached through people being convinced about the positive effects of the HSR system. The model forecasts that the passenger amounts will grow within the range of $7-26 \%$ in the years 2018-2023 (slowing gradually down), and this growth will thereafter slow down to $7 \%$ and below as the year 2030 is reached.

Concerning passenger-km it was forecast in the Bass diffusion model that this will reach $1,500,000$ million passenger-km in the model (2.55 times higher as compared to the realized amount in 2017). At the end of the forecasting period, this was nearly achieved with 1,476,010 passenger-km (Figure 2). The innovative demand had a value of 0.0165 (higher than in the plain passenger model of Figure 1), and imitative demand was 0.294 (lower than in the passenger model). The fitted Bass diffusion model was able to forecast the realized values in a rather good fashion, 99.8\%.

In the last Bass diffusion model, concerning highspeed railway network length, it was assumed in the "high" scenario that the network will reach the length of 45,000 km (given in [1]; 1.79 times higher as compared to the realized amount in 2017). Based on the fitted Bass model the network size should be 44,565.7 $\mathrm{km}$ in the year 2030. The innovative demand (0.0335) in this model was the highest from all three; however, the imitative demand was the lowest (0.2515). The explanation power to the realized data was high as the $R^{2}$ value was $99.3 \%$. However, the realized values of the network size have fluctuated above and below the fitter curve for the entire realized period. As high-speed railway network construction is a delayed activity with financial constraints and budgets as well as technical construction issues, this is understandable. The construction could still be on the way towards $45,000 \mathrm{~km}$

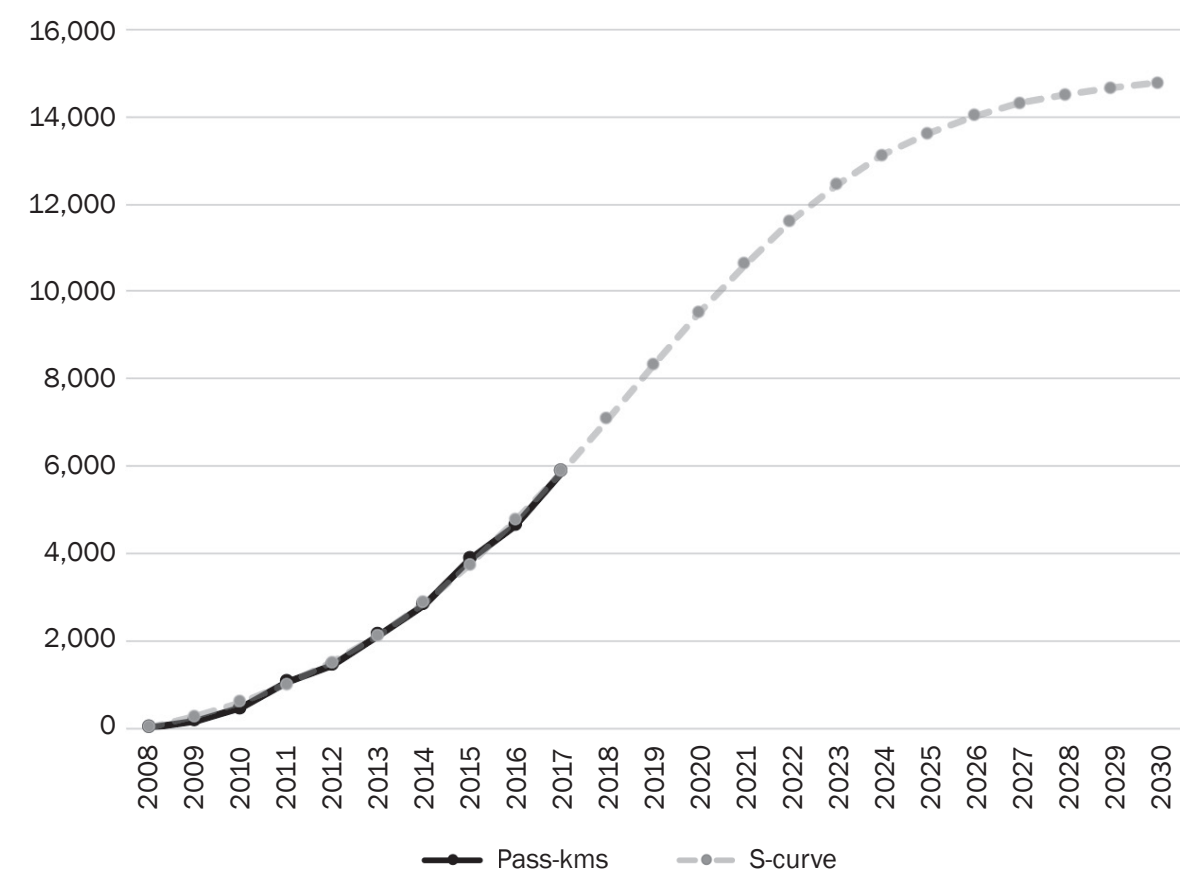

Figure 2 - Realized passenger-km amounts (in 100 mill.) on the Chinese high-speed railway network during 2008-2017, and S-curve based forecast up to the year $2030\left(m=15,000, p=0.0165, q=0.294 ; R^{2}=0.998\right)$ 

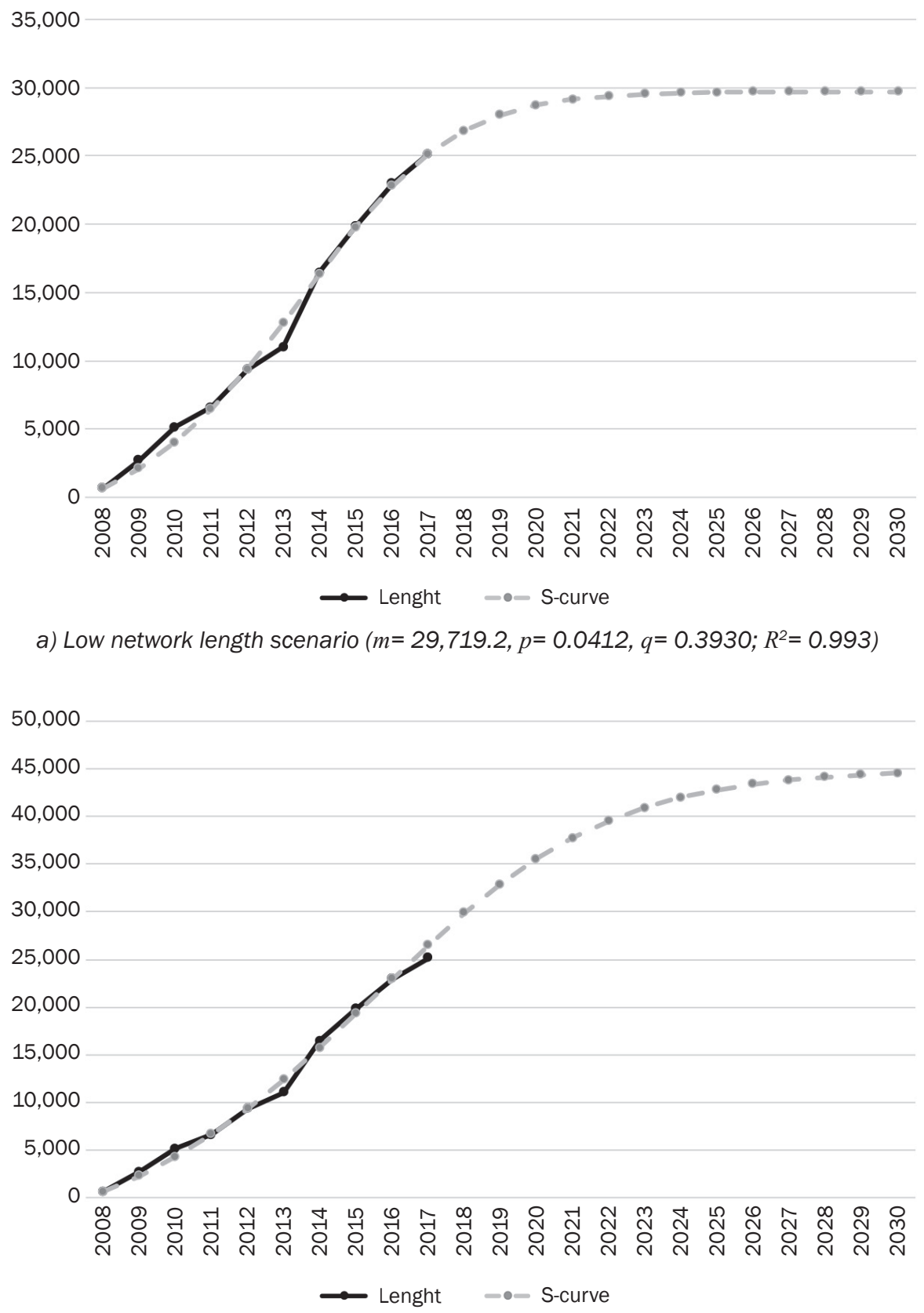

b) High network length scenario $\left(m=45,000, p=0.0335, q=0.2515 ; R^{2}=0.993\right.$

Figure 3 - Realized network length of Chinese high-speed railway network during 2008-2017, and S-curve based forecast up to the year 2030

network size, even if the last two years of the realized observations could indicate differently. However, in the "low" scenario network the length will be 29,719.2 km, with the same $R^{2}$ value as the "high" scenario. The innovative and imitative demand have the highest multipliers of all three, Figures 1-3.

The railway industry and the above estimated diffusion parameter values for three variables of the Chinese HSR are rather conservative, if compared to other branches and industries. Turk \& Trkman [27] estimated the broadband adaption rates in the European OECD member countries. The innovation co-efficient of $p$ in this study ranged in different evaluated countries from 0.011 to 0.099 , and in comparison all the above shown S-curves had rather moderate $p$-values, where the railway network was having the highest, 0.0412 . However, the situation reminding a bit of the railways was the study of Lim et al. [28], which estimated mobile network of $2 \mathrm{G}$ and $3 \mathrm{G}$ adaption rates in the Chinese provinces, and $p$-values were typically below 0.01 . Regarding the imitation rate $q$, Turk \& Trkman [27] reported rates starting typically from 0.4 to 0.5 , and ending as high as just below 0.9. The models in the above Chinese HSR have the imitation rates 
typically below this range; however, they share the similarities with the mobile network adaption rates of Lim et al. [28]. Also, the study made regarding medical devices field yields similar values with HSR, further stressing the conservative diffusion speed of critical transportation infrastructure [29].

\section{RESEARCH METHODOLOGY}

High-speed railway data are rather difficult to gather in a detailed manner, and this would require quite a lot of linking different sources together (e.g. [13]), while also having doubts about the overall data reliability. However, there are limited data available at UIC (2019), where network lengths are reported based on speed classes $(250 \mathrm{~km} / \mathrm{h}$ and $160 \mathrm{~km} / \mathrm{h})$. The amount of passengers and passenger-km are annually reported from the outputs. These data are available from a long-time period, starting from 1996 in some countries and ending in 2017 (not all countries have the data available for the last observation year). Data include 20 countries; however, these do not all have available data for each year, and for a particular year, the data could be limited. All major HS railway countries are available in this database. For the Chinese data, we also used the National Bureau of Statistics of China [23] to get the data for the year 2017, as it was not yet available at UIC [22].
The database also contains data from the train runs of HS traffic. However, these are limited data and not all countries report them to UIC [22]. Therefore, these were not taken as part of this analysis, even if they would have been the key indicator of operational availability and efficiency. Similarly, it would be important to have integrated passenger coaches / trains included in this analysis, but these data are also somewhat limited, and they are disturbed by the use of these units in both conventional passenger transport, and HS transport.

The used DEA model is rather simple in this research as it consists of only two inputs and two outputs. It basically measures the investment efficiency regarding the usage of HS network (Figure 4). It is also true that these measures might have positive correlations with each other, and especially the outputs. This issue was highlighted in the research by Lin [30] as a possible caveat in transportation DEA efficiency models. For this reason, the correlation analysis was completed from all four factors, which is shown in Table 1.

Regarding the used inputs, they seem to have no relationship with each other, and this possible relationship is not statistically significant by any means. Similarly, HS network having maximum speed of 160 $\mathrm{km} / \mathrm{h}$ is not having any statistically significant relationship with two outputs. The situation of this lower speed network variable and its relationship could be explained with the development of HS railway data. In

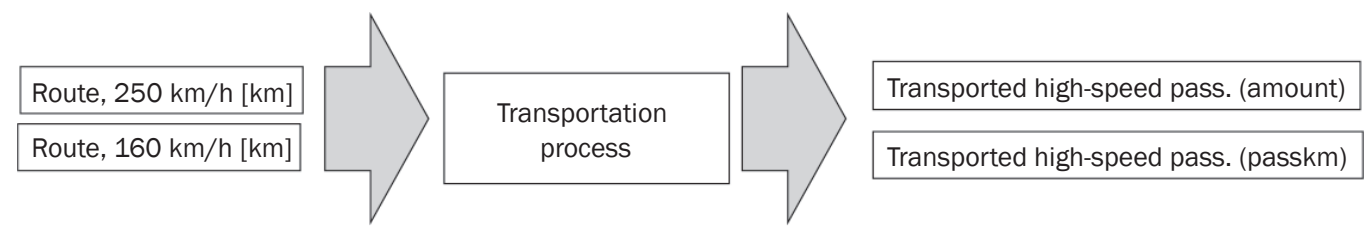

Figure 4 - DEA models used in this study for UIC high-speed railway data

Table 1 - Correlation coefficients between used input and output variables in UIC data high-speed railway DEA models $(n=147)$

\begin{tabular}{|c|c|c|c|c|c|}
\hline & & Tracks $250 \mathrm{~km} / \mathrm{h}$ & Tracks 160 km/h & Pass & Pass km \\
\hline \multirow{3}{*}{ Tracks 250 km/h } & Pearson correlation & 1 & -0.030 &, $941^{* \star}$ &, $972^{* *}$ \\
\hline & Sig. (2-tailed) & & 0.720 & 0.000 & 0.000 \\
\hline & $n$ & 147 & 147 & 147 & 147 \\
\hline \multirow{3}{*}{ Tracks $160 \mathrm{~km} / \mathrm{h}$} & Pearson correlation & -0.030 & 1 & -0.068 & -0.034 \\
\hline & Sig. (2-tailed) & 0.720 & & 0.415 & 0.683 \\
\hline & $n$ & 147 & 147 & 147 & 147 \\
\hline \multirow{3}{*}{ Pass } & Pearson correlation & $941^{* *}$ & -0.068 & 1 & ,989** \\
\hline & Sig. (2-tailed) & 0.000 & 0.415 & & 0.000 \\
\hline & $n$ & 147 & 147 & 147 & 147 \\
\hline \multirow{3}{*}{ Pass km } & Pearson correlation &, $972^{* *}$ & -0.034 &, $989^{* *}$ & 1 \\
\hline & Sig. (2-tailed) & 0.000 & 0.683 & 0.00 & \\
\hline & $n$ & 147 & 147 & 147 & 147 \\
\hline
\end{tabular}

${ }^{* *}$ Correlation is significant at the 0.01 level (2-tailed) 
the earlier years, many countries had sections where lower speeds were an important part of HS network. However, during the recent years (and decade) data have indicated that many countries have upgraded their network, and lower speed sections have an increasingly less significant role among the countries. There is only a limited number of countries which have this lower speed class growing within the HS network. One such country is Finland, which does not have any railway networks for higher speed class at all (250 $\mathrm{km} / \mathrm{h})$.

Three remaining variables in the used DEA model have high positive correlation with each other, and in all three cases this is highly statistically significant. The highest correlation is between two outputs, which was to be assumed a priori. So, the following results could have a bias mostly due to the output correlation with each other; however, between the inputs this sort of correlation does not exist at all. It is also notable that only one input factor has a correlation to the output (it would be desirable in efficiency analysis models that inputs lead to outputs). It should be highlighted that nearly all service models have reported features, and inputs and outputs often have undesired correlations with each other. This is mostly due to non-inventory nature of business, and in HS railway it is rather natural (or air transport) as these systems are built to serve longer distances.

In the efficiency analysis of this research work, all years from different countries are pooled together as one dataset, and only one efficiency calculation for all observations is performed. This increases the reliability of analysis as in the individual years the observation amounts do vary, and in some years the amounts are rather limited. For efficiency analysis EMS software (ver. 1.3.0) is used, which is an old and often applied computation program for the frontier analysis. As this research is interesting for the larger HS railway countries, it was found that DEA frontier assumes "constant return on scale" (CCR), and the models are input-oriented [31]. The "variable return on scale" efficiency frontier could have been used, and this would have assured fairer treatment of smaller countries. However, this research is interesting from the larger HS railway countries, and also it was found in the analysis that smaller countries reached on some occasions near frontier or even recorded $100 \%$ efficiency with CCR frontier (like Finland during the years 2008 and 2010).

\section{EFFICIENCY ANALYSIS OF HIGH-SPEED RAILWAYS}

All the listed countries of UIC (2019) database were included in the DEA efficiency analysis, and it consists of such countries which have only a very small amount of high-speed railway network with lower speed (tracks $160 \mathrm{~km} / \mathrm{h}$ ), but also all larger high-speed rail countries having mostly higher high-speed network (tracks 250 $\mathrm{km} / \mathrm{h}$ ). All the years of data were included in one DEA model, and the amount of evaluated countries with different years was 148 (all efficiency values of different countries are reported in Figure 5 based on this). Next, the efficiency level was forecast also with the Bass diffusion model values from Section 2, and the number of evaluated decision-making units was in the larger forecasting dataset 174 (13 years of Chinese forecast Bass diffusion model data from two alternative scenarios).

The differences of efficiency among countries and years was significant. Figure 4 shows only the highest performing countries, and it excludes such countries like Spain and Turkey. Both of these were having low efficiency during the analysis period. In Turkey, the efficiency was below $10 \%$ all the time and in turn in Spain it was below $20 \%$. Six other larger HSR countries did also have differences in their efficiencies as shown in Figure 4. All European countries in the early period of the analysis were showing similar levels of efficiency, around 50-60\%. However, after 2005, the Italian efficiency started to show weaknesses and eventually dropped to the level of $40 \%$. Other older European high-speed countries, Germany and France, maintained the level of $50-60 \%$ for the entire period. The Asian countries showed in general better performance than the Europeans and this concerns Japan and South Korea. These two Asian countries were also the only countries in this study which were able to record the frontier efficiency of 100\% (South Korea in 2008 and Japan in 2015). China's performance started from very low levels in the inauguration of high-speed railway implementation and use (2008), but increased from below $10 \%$ efficiency to nearly $50 \%$ in 2017 . China is already above Italy in its efficiency and catching up with Germany and France.

In Figure 5 two different methods are used to forecast China's efficiency performance in the forthcoming decade. Linear regression model fitted on the realized Chinese efficiency level would suggest that China will surpass Germany and France in 2020, and it ought to reach in general the level of Japan and South Korea (efficiency of $80 \%$ ) in 2023 . It should be noted that South Korean HSR efficiency declined in the analysis rather significantly in 2015-2016, and if this level is the new performance standard, then China will surpass South Korea earlier. The linear model has been rather a good forecaster of China's efficiency development as its $R^{2}$ value is $88.47 \%$. So, time alone explains this significant amount of efficiency development.

The Bass diffusion analysis in Section 2 contained all the main variables of DEA model concerning China forecast until 2030. These values were included in the DEA model with the name of "China*" (high scenario) and "China**" (low scenario). The Bass model fitted best the forecast (from past data) passenger-km 


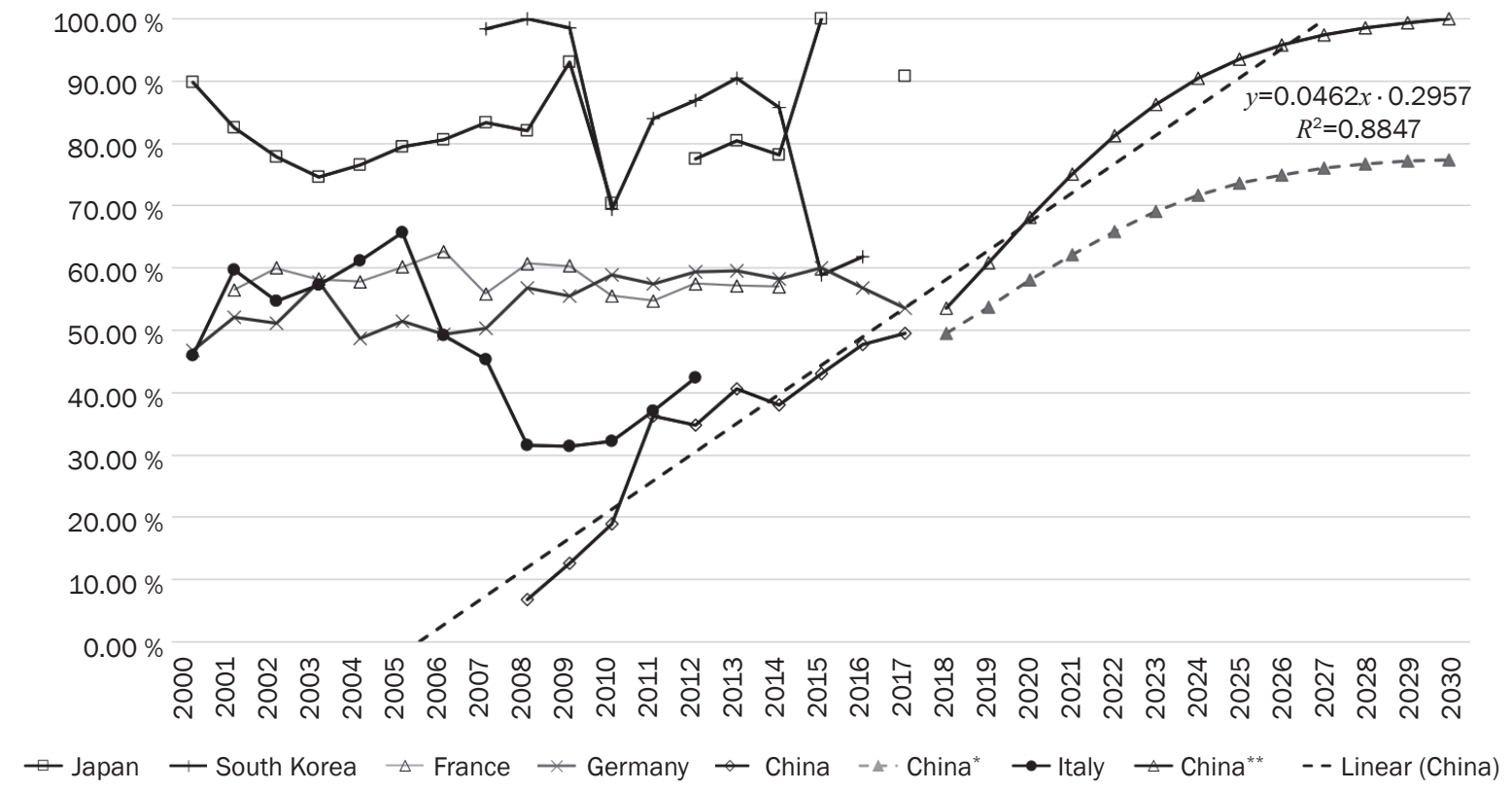

Figure 5 - Efficiency performance of the leading high-speed railway countries in the world and linear regression (Linear (China)) as well as Bass diffusion (China ${ }^{\star}$, and China ${ }^{* \star}$ series)-based forecasts for Chinese efficiency development for 2018-2030

volume of high-speed travel; however, passengers as well as railway network length (tracks) had high explanation values, too. In the recent years (2016-2017) the Bass diffusion model was a little bit over the forecast railway network length than the one realized in the high scenario. Therefore, it is understandable that the China* series efficiency is somewhat lower in the first forecast year of 2018 as compared to 2017. Based on the Bass diffusion models forecasting Germany and France will be surpassed in 2020 (low scenario) or 2021 (high scenario), and in the very end of the forecasting period the Chinese efficiency will reach the level of $77.5 \%$ (high scenario) or $100 \%$ (low scenario). The former is the lower end of the South Korean and Japanese high-speed efficiency area. So, it could be argued that China's efficiency will nearly match those of the leading Asian countries in 2028-2030 in any case. However, if HSR network will reach only the "low scenario" length, and materialize moderate passenger amounts used in this scenario, HSR will have really high efficiency. This, of course, requires high growth of the passenger-km.

\section{CONCLUSION}

Building long-term and critical transportation infrastructure is always a challenging task, and getting the users interested in the new transportation option is another part of the success equation. It was therefore, surprising that the Chinese HSR investment improved in the first decade so much its efficiency, simultaneously being in the expansion phase of the railway network. Even at the moment the used efficiency model shows that the Chinese HSR is decently efficient as compared to its international peers. However, reaching higher levels and possibly the highest performing countries, will take some years, if not approximately a decade of time. Based on the linear regression model, China ought to catch up with the most efficient countries in HSR during the following decade. However, the Bass diffusion model based forecast indicates a slower improvement in efficiency (high scenario). Another Bass diffusion model indicated the development rather similar with the linear regression model, and eventually reaching the frontier efficiency. Both Bass diffusion model forecasts seem to be more realistic as compared to the linear model as they are based on the numbers of different variables, which are forecast through a diffusion model. The linear growth could continue for some time, e.g. in the passenger amounts or passenger-km, but at some point in time this will start to slow down and mature. It is just one basic model of large-scale system behaviour.

Other countries in the study were assumed to remain in the neighbourhood of their current performance, and the variables were not expected to change in the following decade. This is the most likely scenario. However, there are some possibilities even for the declining performance. For example, the population in Japan, Germany, France and Italy is hardly growing at all, or it is even in a small decline. If this population shows a decline in the following decade, it could mean that a larger proportion of people in particular country live in the larger cities or capitals. This, in turn, could mean that the daily or weekly transportation needs of people do not grow at all any more, and they could even show 
declining trends (e.g. situation in Hokkaido, Japan, see [32]). However, it is unclear what will happen for HSR in this scenario as it is one of the most sustainable transportation modes (supporting growth), and it is the most convenient transportation mode for the ageing societies (vs. private cars). As telecommunications and transport use and needs have developed over a long time in a similar fashion [33], it could be assumed that the forthcoming growth in the fast mobile Internet will support sustainable transportation needs.

For further research, it would be interesting to continue with the methods developed in this research work. Integrating Bass diffusion models and future efficiency performance of the decision-making unit is a very interesting area, and could be applied in other branches as well (e.g. implementation of new technologies, like $5 \mathrm{G}$ or electrical vehicles). As another application area it would be interesting to follow the transition of very high-speed railway construction to the implementation and use phase - train units reaching speeds of $350 \mathrm{~km} / \mathrm{h}$ and above.

李卫东博士 教授, 希尔莫拉 奥利-派柯 博士 教授, 武 剑红 博士 教授

\section{摘要:}

中国高速铁路（HSR）网络建设于 2000 年初启动，其 后开始大规模建设, 2008年后进入大规模使用阶段。此 后, 中国高速铁路扩张速度令人印象深刻。如果以在扩张 阶段高速铁路已应用数量为评估目标的话, 高速铁路网络 投资可以被认为是成功的。本研究中构建的扩散模型显 示, 高速铁路网络扩张和乘客增长将至少持续到下一个十 年之内。文中运用数据包络分析模型评价绩效。结果表 明, 中国高速铁路效率从很低的水平开始, 但它随着高速 铁路网络的扩展而增加。目前, 高速铁路效率接近欧洲领 先高速铁路国家（德国和法国）的水平。然而，通过线性 模型和巴斯扩散模型预测，未来十年中国高速铁路效率将 达到日本和韩国的标准水平。网络长度稍长, 乘客相对增 长较小, 但随着客运周转量的快速增长, 似乎有可能达到 前沿效率水平。

\section{关键词:}

高速铁路，效率，比较，巴斯扩散模型，未来

\section{REFERENCES}

[1] Wang L, Liu Y, Mao L, Sun C. Potential impacts of China 2030 high-speed rail network on ground transportation accessibility. Sustainability. 2018;10(4): 1270. Available from: doi:10.3390/su10041270

[2] He N, Li J, Wang Y, Ma C. Rail-induced traffic in China. Promet - Traffic\&Transportation. 2017;29(5): 511-520.

[3] Huang Y. Understanding China's Belt \& Road Initiative: Motivation, framework and assessment. China Economic Review. 2016;40: 314-321.

[4] Du J, Zhang Y. Does One Belt One Road initiative promote Chinese overseas direct investment? China Economic Review. 2018;47: 189-205.

[5] He H. Key challenges and countermeasures with railway accessibility along the Silk Route. Engineering. 2016;2: 288-291.

[6] Jiang Y, Sheu J-B, Peng Z, Yu B. Hinterland patterns of China Railway (CR) express in China under the Belt and Road Initiative: A preliminary analysis. Transportation Research Part E. 2018;119: 189-201.

[7] Hilmola O-P, Henttu V, Panova Y. (2018). Development of Asian landbridge from Finland: Current state and future prospects. $22^{\text {nd }}$ Cambridge International Manufacturing Symposium, University of Cambridge, UK, 2728 September 2018. Available from: https://www.repository.cam.ac.uk/handle/1810/284350 [Accessed $20^{\text {th }}$ Dec 2018].

[8] Wang Y, Han B-M, Wang J-K. A passenger flow routing model for high-speed railway network in different transportation organization modes. Promet - Traffic \& Transportation. 2018;30(6): 671-682.

[9] Gao Y, Li W, You X. Research on the Efficiency Evaluation of China's Railway Transport Enterprises with Network DEA. China Soft Science. 2011;5: 176-182.

[10] Hilmola O-P. Benchmarking global railway freight transportation efficiency during the period of 1980-2004. International Journal of Shipping and Transport Logistics. 2009;1(4): 311-328.

[11] Hilmola O-P. Global railway passenger transports - Efficiency analysis from period of 1980-2004. International Journal of Logistics Economics and Globalisation. 2009;2(1): 23-39.

[12] Li Y, Li X, Wang S. Does the Reform of the Ministry of Railways and the Entry of High-speed Railway Improve the Technical Efficiency of the Railway Industry? Reform of Economic System. 2018;4: 179-186.

[13] Domernik JE. Performance and efficiency of highspeed rail systems. Transportation Research Procedia. 2015;8: 136-144.

[14] Beria P, Grimaldi R, Albalate D, Bel G. Delusions of success: Costs and demand of high-speed rail in Italy and Spain. Transport Policy. 2018;68: 63-79.

[15] Jiang C, Li X. Low cost carrier and high-speed rail: A macroeconomic comparison between Japan and Western Europe. Research in Transportation Business and Management. 2016;21: 3-10.

[16] Zhang Q, Yang $\mathrm{H}$, Wang Q. Impact of high-speed rail on China's big three airlines. Transportation Research Part A. 2017;98: 77-85.

[17] Li H, Strauss J, Lu L. The impact of high-speed rail on civil aviation in China. Transport Policy. 2019;74: 187-200.

[18] Álvarez-SanJaime Ó, Cantos-Sanchez P, Moner-Colonques R, Sempere-Monerris JJ. Rail access charges and internal competition in high-speed trains. Transport Policy. 2016;49: 184-195.

[19] Couto A. The effect of high-speed technology on European railway productivity growth. Journal of Rail Transport Planning \& Management. 2011;1: 80-88.

[20] Wetwitoo J, Kato H. High-speed rail and regional economic productivity through agglomeration and network externality: A case study of inter-regional transportation in Japan. Case Studies in Transport Policy. 2017;5: 549-559.

[21] Liu L, Zhang M. High-speed rail impacts on travel times, accessibility, and economic productivity: A benchmarking analysis in city-cluster regions of China. Journal of Transport Geography. 2018;73: 25-40. 
[22] UIC Railisa - UIC Statistics. Available from: https://uicstats.uic.org/ [Accessed 10 ${ }^{\text {th }}$ Jan 2019].

[23] National Bureau of Statistics of China. China Statistical Yearbook 2018. China Statistics Press, Beijing. Available from: http://www.stats.gov.cn/tjsj/ndsj/2018/ indexeh.htm [Accessed $27^{\text {th }}$ Jan 2019].

[24] Dent HS. The Demographic Cliff - How to Survive and Prosper During the Great Deflation of 2014-2019. New York: Penguin Group; 2014.

[25] OECD. OECD Urban Policy Reviews: China 2015. OECD Urban Policy Reviews, OECD Publishing, Paris. Available from: doi:10.1787/9789264230040-en [Accessed 15 ${ }^{\text {th }}$ Jan 2019].

[26] WorldBank.Urbanpopulation(\%oftotal).Availablefrom: https://data.worldbank.org/indicator/SP.URB.TOTL. IN.ZS?year_high_desc=true [Accessed 22 ${ }^{\text {nd }}$ March 2019].

[27] Turk T, Trkman P. Bass model estimates for broadband diffusion in European countries. Technological Forecasting and Social Change. 2012;79: 85-96.

[28] Lim J, Nam C, Kim S, Rhee H, Lee E, Lee H. Forecasting
3G mobile subscription in China: A study based on stochastic frontier analysis and a Bass diffusion model. Telecommunications Policy. 2012;36: 858-871.

[29] Ganjeizadeh F, Lei H, Goraya P, Olivar E. Applying lookslike analysis and Bass diffusion model techniques to forecast a neurostimulator device with no historical data. Procedia Manufacturing. 2017;11: 1916-1924.

[30] Lin ETJ. Route-based performance evaluation of Taiwanese domestic airlines using data envelopment analysis: a comment. Transportation Research Part E: Logistics and Transportation Review. 2007;44(5): 894-899.

[31] Charnes A, Cooper WW, Rhodes E. Measuring the efficiency of decision making units. European Journal of Operational Research. 1978;2(6): 429-444.

[32] Kurosaki F, Alexandersson G. Managing unprofitable passenger rail operations in Japan - Lessons from the experience in Sweden. Research in Transportation Economics. 2018;69: 460-469.

[33] Bertolini L. Future of transport? - Future of cities! Promet - Traffic - Traffico. 1999;11(2-3): 89-95. 